\title{
Life Stage
}

National Cancer Institute

\section{Source}

National Cancer Institute. Life Stage. NCI Thesaurus. Code C89335.

A designation assigned to a particular period during a life cycle, generally defined by chronological parameters. 